\title{
Sleep duration and body composition in adolescents
}

\author{
L. Mamluk, L. J. Murray, M. M. Cantwell and on behalf of the YH 2000 Study Group \\ School of Medicine, Dentistry and Biomedical Sciences, Centre for Public Health, Queen's University Belfast, \\ BT12 6BJ, UK
}

The complexity of obesity pathogenesis requires the identification of novel risk factors. Increasing research suggests a relationship between sleep duration and obesity in adults ${ }^{(1)}$ and children ${ }^{(2)}$; however, evidence in adolescents is scarce. Adolescence may be a crucial period for the modification of obesity risk factors and therefore in the prevention of its detrimental outcomes in adulthood ${ }^{(3)}$. This study aims to examine the relationship between sleep duration and weight-related parameters in adolescents.

Data from the Young Hearts 2000, a cross-sectional cohort study carried out in 1999-2001 ${ }^{(4)}$, were examined. The 2017 participants from Northern Ireland were aged 12 and 15 years. The relationship between BMI $z$-scores, waist circumference and skin-fold thickness and self-reported sleep variables was investigated using linear regression, gender stratified analyses after adjusting for age, energy intake, physical activity, smoking, pubertal status, social class and T.V. viewing.

The prevalence of obesity and overweight was 4.4 and $15.8 \%$, respectively. Mean sleep duration on school days was $8.9(0.95) \mathrm{h}$ and 10.2(1.3) h during weekends $(P<0.0001)$. Average sleep duration per day (school days and weekends) was $9.24(0.81)$ h. Duration of average night-time sleep per day was negatively associated with BMI $z$-score and waist circumference after adjusting for confounders, as shown in the table. For every hour increase in sleep duration, an $\sim 0.1$ reduction in BMI $z$-scores and $6.8 \mathrm{~mm}$ in waist circumference was shown. The same relationship was not observed for $\%$ body fat. When stratified by gender, sleep duration was not associated with measures of obesity in females, however, remained significant in males for BMI $z$-score and waist circumference. An hour increase in sleep duration was associated with a 0.13 lower BMI $z$-score and a $12 \mathrm{~mm}$ reduction in waist circumference.

\begin{tabular}{|c|c|c|c|c|c|c|c|c|c|}
\hline & \multicolumn{9}{|c|}{ Gender } \\
\hline & \multicolumn{3}{|c|}{ Total sample ( $n$ 2017) } & \multicolumn{3}{|c|}{ Males $(n$ 1019) } & \multicolumn{3}{|c|}{ Females ( $n$ 998) } \\
\hline & Coefficient & SE & $P$ & Coefficient & SE & $P$ & Coefficient & SE & $P$ \\
\hline BMI $z$-score* & -0.099 & 0.034 & 0.004 & -0.128 & 0.048 & 0.007 & -0.057 & -0.050 & 0.249 \\
\hline Waist circumference (mm) & -6.757 & 3.069 & 0.028 & -12.153 & 4.303 & 0.005 & 0.324 & 4.398 & 0.941 \\
\hline$\%$ Body fat & 0.019 & 0.209 & 0.928 & -0.223 & 0.291 & 0.443 & 0.216 & 0.303 & 0.476 \\
\hline
\end{tabular}

*UK 1990 reference data ${ }^{(5)}$.

The results confirm the role of sleep duration as an independent risk factor for adolescent overweight and obesity in boys. The current study introduces the concept that sleep duration could be of importance even in populations with overall sleeping habits within recommendations. However, more research is needed to establish prospective relationships and outline the mechanisms involved.

1. Hasler G, Buysse DJ, Klaghofer R et al. (2004) Sleep 27, 661-666.

2. Reilly JJ, Armstrong J, Dorosty AR et al. (2005) Br Med J 330, 1357.

3. Dietz WH (2004) N Engl J Med 350, 855-857.

4. Watkins DC, Murray LJ, McCarron P et al. (2005) Int J Obes 29, 579-585.

5. Cole TJ, Freeman JV \& Preece MA (1995) Arch Dis Child 73, 25-29. 